\title{
BEST PRACTICES : KAJIAN EFEKTIFITAS PENERAPAN STAKEHOLDERS MAPPING SEBAGAI SISTEM PENCEGAHAN DINI TERJADINYA KONFLIK SOSIAL DI PERTAMBANGAN EMAS PT BUMI SUKSESINDO
}

\author{
Muhamad Zambani, Makinudin Marniadi, Budi Nuraini dan \\ Tri Sakti Kurniawan ${ }^{1)}$
}

1) Team Community Relation, PT. Bumi Suksesindo

\begin{abstract}
ABSTRAK
Pada bulan November 2015 PT Bumi Suksesindo mengalami pembakaran beberapa fasilitas perusahaan oleh aksi masa tolak tambang yang mengakibatkan beberapa fasilitas milik perusahaan rusak parah, mulai dari gudang mesin diesel, genset serta gudang peralatan. Belajar dari pengalaman itu, maka diperlukan sistem pencegahan konflik secara dini agar tidak terjadi lagi kasus yang serupa. Kajian ini bertujuan untuk mengetahui efektifitas stakeholders mapping sebagai upaya pencegahan dini terjadinya konflik sosial di pertambangan emas PT Bumi Suksesindo. Kajian yang telah dilakukan dengan cara pengelompokkan stakeholders berdasarkan internal dan eksternal, ketergantungan stakeholder dengan perusahaan, power dan interest stakeholder, serta posisi stratejik stakeholder maka dapat diketahui bagaimana strategi dan teknik mengelola stakeholders tersebut sehingga tidak berlanjut kepada aksi masa yang lebih besar yang dapat merugikan baik perusahaan maupun pemerintah. Dari analisis terebut diketahui stakeholder kunci yang perlu mendapat perhatian utama dalam pencegahan dini terjadinya konflik adalah kelompok tolak tambang, kelompok "preman jalan" jalur logistic, dan kelompok tapak tambang (kelompok paling dekat dengan operasional tambang). Pengelolaan hubungan stakeholders dengan yang cara yang tepat selain dapat mencegah terjadinya konflik juga dapat mengenali potensi dan aspirasi stakeholders yang dapat membuka peluang untuk mengembangkan kesejahteraan masyarakat sebagai sebagai prasyarat utama untuk menjamin keberlanjutan perusahaan.
\end{abstract}

Kata Kunci: PT Bumi Suksesindo, stakehoders mapping, sistem pencegahan konflik, konflik sosial

\begin{abstract}
In November 2015 PT Bumi Suksesindo experienced the burning of a number of company facilities by the anti-mining group action which resulted in severely damaged company-owned facilities such as diesel engine warehouses, generator sets and equipment warehouses. The lesson learned community relation team really need an early conflict prevention system is needed so that similar cases do not occur again. This study aims to determine the effectiveness of stakeholder mapping as an effort to prevent early social conflicts in the PT Bumi Suksesindo gold mine. The study has been conducted by grouping stakeholders analysis based on internal and external, dependence of stakeholders with the company, stakeholders' power and interests, as well as the strategic position of stakeholders so it can be seen how the strategies and techniques of managing these stakeholders so that it does not continue to greater mass actions and harm both the company and government. From this analysis, it is known that the key stakeholders that need to be given the main attention in the early prevention of conflict are the anti-mining group, the logistical road group, and the community around mining group. Management of stakeholder relations in the right way in addition to preventing conflict can also recognize the potential and aspirations of stakeholders so that it even opens opportunities to develop community welfare as the main prerequisite for ensuring the sustainability of the company.
\end{abstract}

Keywords: PT Bumi Suksesindo, stakeholder mapping, conflict prevention systems, social conflict. 


\section{A. PENDAHULUAN}

\section{A.1. Latar belakang}

Proyek Tambang Emas dan mineral pengikutnya (DMP) Tujuh Bukit yang berlokasi di Desa Sumberagung, Kecamatan Pesanggaran, Kabupaten Bayuwangi telah dikembangkan oleh PT. Bumi Suksesindo (PT. BSI) sebagai pemegang Ijin Usaha Pertambangan (IUP). Operasi Produksi berdasarkan Surat Keputusan Bupati Banyuwangi No. 188/547/KEP/429.011/2012 untuk jangka waktu 20 tahun yang berlaku surut terhitung mulai 25 Januari 2010. Lokasi proyek terletak \pm 60 $\mathrm{km}$ ke arah Barat Daya dari pusat pemerintahan Kabupaten Banyuwangi, dan $\pm 205 \mathrm{~km}$ ke arah Tenggara dari pusat pemerintahan Provinsi Jawa Timur.

Proyek Tujuh Bukit saat ini telah berada pada tahap operasi produksi untuk menambang dan mengolah cadangan bijih emas yang berupa endapan epitermal sulfidasi tinggi (epithermal high sulfidation gold deposit) yang telah teroksidasi atau dalam dokumen ini selanjutnya disebut dengan cadangan oksida di dalam area prospek Tujuh Bukit. Saat ini, kegiatan penambangan dilakukan dengan menerapkan sistem metode penambangan terbuka dengan laju penambangan bijih hingga 4 juta ton pertahun. Bijih dari lubang tambang (pit) diangkut menuju ke area penyiapan bijih (ore preparation plant-OPP) untuk diremukkan dan diaglomerasi dan kemudian diangkut menuju area pelindian (heap leach pad/ HLP). Pada HLP bijih akan ditumpuk dan disiram menggunakan larutan pelindi yang mengandung sianida untuk mengekstrasi logam-logam berharga seperti emas dan perak dari batuan bijih teraglomerasi. Air hasil lindian (pregnant leachate solution) akan dikumpulkan dan dipompa menuju area pengolahan yang menerapkan sistem adsorption desorption and recovery (ADR) untuk proses perolehan emas dan perak. Sirkuit perolehan emas dan perak ini terdiri dari sirkuit carbon in column (CIC), regenerasi karbon dan elusi. Emas dan perak akan diperoleh melalui proses electrowinning dan peleburan menjadi dore. Produk dari pengolahan ini berupa dore batangan yang mengandung sekitar $77 \%$ emas dan $23 \%$ perak yang kemudian dikirim ke unit pemurnian (refinery) milik PT. ANTAM di Jakarta untuk diproses lebih lanjut untuk menghasilkan emas dan perak sesuai dengan standard pasar.

Seiring dengan kegiatan operasi produksi dan eksplorasi pengembangan tersebut, kegiatan reklamasi dan rehabilitasi progresif pada beberapa area yang tidak lagi diperlukan untuk kegiatan operasi telah dilakukan pada tahap persiapan penambangan dan tahap awal operasi. PT BSI mendapatkan penghargaan untuk kegiatan reklamasi ini dari Kementrian Kehutanan pada tahun 2019.

Selain itu, kegiatan pengelolaan lingkungan berupa penerimaan tenaga lokal, pelaksanaan tanggung jawab sosial perusahaan (corporate social responsibility-CSR) juga telah dilaksanakan. CSR tersebut telah dilaksanakan oleh PT. BSI pada bidang pemberdayaan ekonomi, pendidikan, kesehatan, infrastruktur sarana publik, sosial, budaya, keagamaan serta penguatan kelembagaan. Sebagai pemenuhan kewajiban perusahaan terhadap dokumen Amdal yang telah disusun dan disepakati, pemantauan kualitas lingkungan juga telah dilakukan oleh PT. BSI dengan melibatkan pihak ketiga (laboratorium terakreditasi) dan telah dilakukan pelaporan secara rutin yang diserahkan kepada pihak terkait khususnya instansi yang bertanggung jawab di bidang pengelolaan lingkungan hidup setiap 3 bulan.

Dalam hubungan dengan masyarakat sekitar tambang, PT BSI mengalami dinamika hubungan dengan masyarakat yang menamakan dirinya kelompok tolak tambang. Kelompok ini didukung oleh Lembaga Swadaya Masyarakat yang bergerak dalam advokasi lingkungan hidup berusaha mempengaruhi masyarakat lainnya untuk menolak operasional PT BSI. Puncak konflik sosial terjadi pada tahun 2015 yang berujung pada pembakaran beberapa fasilitas operasional PT BSI oleh massa. Pada tahun 2016 sampai 2018 konflik sosial masih tetap berlangsung berupa aksi massa, menuntut agar PT BSI membangun jalan yang kondisinya rusak serta ada penolakan pemasangan kabel listrik dari PLN untuk operasional PT BSI. 


\section{A.2. Tujuan}

Kajian efektivitas stakeholders mapping terhadap pencegahan secara dini konflik secara dini ini bertujuan untuk:

a. Mengetahui sejauh mana stakeholder mapping ini efektif untuk mengidentifikasi para pihak yang mendukung, berlawanan dan berada diantaranya terhadap PT BSI.

b. Mengidentifikasi bagaimana strategi dan cara mengelola stakeholders berdasarkan karakteristriknya agar berhasil guna dan tepat guna.

c. Mengetahui sejauh mana stakeholders mapping ini efektif berdampak menurunkan intensitas aksi massa kepada PT BSI.

\section{A.3. Pendekatan pemecahan masalah}

Arahan management PT BSI agar melakukan pendekatan pemecahan masalah konflik ini secara persuasif dan damai dengan mengedepankan komunikasi dan dialog-dialog untuk mencari solusi bersama, yang mendidik dan menyejahterakan masyarakat secara berkelanjutan.

Langkah pemecahan masalah yang dilakukan adalah mengumpulkan data-data pemicu terjadinya konflik, mengkategorikan jenis-jenis konflik yang ada, mengidentifikasi stakeholders yang terlibat secara langsung ataupun tidak langsung terhadap masing-masing kategori konflik, menyusun langkah pendekatan (engagement) kepada masyarakat, melaksanakan strategi dan cara engagement sesuai dengan langkah yang telah ditentukan, kemudian terakhir melihat data-data penyelesesian keluhan dan konflik yang pernah terjadi untuk mengetahui efektifitasnya.

\section{B. METODOLOGI PENELITIAN}

Kajian ini menggunakan metode kualitatif untuk menganalisis penerapan stakeholder mapping pada PT BSI antara lain, studi literatur, peninjauan teori rujukan, studi kasus, interview, kuisioner, dan pengamatan.

Jenis dan sumber data yang penulis gunakan dalam penelitian ini meliputi data primer dan sekunder sebagai berikut:

1. Data Primer

Data primer yang digunakan dalam penelitian ini diperoleh melalui survey dan wawancara sederhana dengan berbagai pihak untuk mendapatkan persepsi mengenai hal-hal yang berhubungan dengan penelitian ini.

2. Data Sekunder

Data sekunder didapatkan dari laporan yang telah disusun oleh PT BSI.

\section{HASIL DAN PEMBAHASAN}

\section{C.1. Penerapan stakeholders mapping}

Potensi terjadinya konflik sosial di PT BSI ada 7 (tujuh) kategori berdasarkan issue yang telah terjadi dalam kurun waktu tahun 2015-2019. Oleh karena itu stakeholders mapping dilakukan berdasarkan 7 (tujuh) kategori tersebut. Teridentifikasi ada 39 (tiga puluh sembilan) stakeholders yang terkait dengan rincian sebagaimana tertera pada Tabel 1.

Selanjutnya dari daftar stakeholders yang ada dikelompokkan berdasarkan posisinya terhadap organisasi menjadi internal dan external stakeholders. Tabel 2. Menunjukkan internal dan eksternal stakeholders terkait managamen konflik dari PT BSI. 
Tabel 1. Daftar Stakeholder berdasarkan potensi konflik pada PT BSI

\begin{tabular}{|c|c|c|c|c|}
\hline No & Potensi Konflik & No & Nama Stakeholder & Deskripsi \\
\hline \multirow[t]{8}{*}{1} & $\begin{array}{l}\text { Ketenaga } \\
\text { kerjaan }\end{array}$ & 1 & HRD PT BSI & $\begin{array}{l}\text { Pihak yang berwenang melaksanakan rekrutmen } \\
\text { karyawan untuk PT BSI }\end{array}$ \\
\hline & & 2 & HRD Kontraktor & $\begin{array}{l}\text { Pihak yang berwenang melaksanakan rekrutmen } \\
\text { karyawan untuk kontraktor }\end{array}$ \\
\hline & & 3 & HRD MMS & $\begin{array}{l}\text { Pihak yang berwenang melaksanakan rekrutmen } \\
\text { karyawan untuk kepentingan projek }\end{array}$ \\
\hline & & 4 & Pencari kerja & $\begin{array}{l}\text { Pihak yang berminat mendapatkan pekerjaan di } \\
\text { lingkungan PT BSI dari masyarakat sekitar tambang } \\
\text { ataupun dari luar. }\end{array}$ \\
\hline & & 5 & Pemerintah desa & $\begin{array}{l}\text { Pihak yang memfasilitasi komunikasi warga desa } \\
\text { dengan PT BSI }\end{array}$ \\
\hline & & 6 & Karyawan & $\begin{array}{l}\text { Karyawan PT BSI ataupun kontraktor yang } \\
\text { menginformasikan kepada kerabat dan tetangganya } \\
\text { tentang lowongan tenaga kerja }\end{array}$ \\
\hline & & 7 & Serikat Pekerja & $\begin{array}{l}\text { Pihak serikat pekerja yang memberikan informasi } \\
\text { adanya lowongan dan membela apabila ada } \\
\text { penyelesaian kontrak kerja. }\end{array}$ \\
\hline & & 8 & Disnaker & $\begin{array}{l}\text { Pihak dari pemerintah yang mengawasi kepatuhan } \\
\text { rekrutmen tenaga kerja. }\end{array}$ \\
\hline \multirow[t]{6}{*}{2} & $\begin{array}{l}\text { Lingkungan } \\
\text { hidup }\end{array}$ & 9 & $\begin{array}{l}\text { Masyarakat sekitar } \\
\text { tambang wilayah IUP }\end{array}$ & $\begin{array}{l}\text { Pihak yang melihat secara langsung terjadinya dugaan } \\
\text { pencemaran baik air ataupun udara }\end{array}$ \\
\hline & & 10 & $\begin{array}{l}\text { Departemen } \\
\text { Environmental PT BSI }\end{array}$ & $\begin{array}{l}\text { Pihak yang bertugas melakukan pengawasan dan } \\
\text { pengendalian pencemaran lingkungan dari opersional } \\
\text { PT BSI dan kontraktor }\end{array}$ \\
\hline & & 11 & $\begin{array}{l}\text { Dinas Lingkungan } \\
\text { Hidup } \\
\text { (provinsi/kabupaten) }\end{array}$ & $\begin{array}{l}\text { Pihak pemerintah yang bertugas melakukan } \\
\text { monitoring dan evaluasi permasalahan lingkuangan } \\
\text { hidup. }\end{array}$ \\
\hline & & 12 & $\begin{array}{l}\text { LSM Lingkungan } \\
\text { hidup/Walhi }\end{array}$ & $\begin{array}{l}\text { Pihak organisasi non pemerintah yang melakukan } \\
\text { advokasi permasalahan lingkungan hidup }\end{array}$ \\
\hline & & 13 & Nelayan & $\begin{array}{l}\text { Pihak masyarakat yang kehidupannya tergantung dari } \\
\text { hasil tangkapan ikan yang sensitif terhadap issue } \\
\text { pencemaran air laut. }\end{array}$ \\
\hline & & 14 & $\begin{array}{l}\text { Kelompok tolak } \\
\text { tambang }\end{array}$ & $\begin{array}{l}\text { Pihak dari masyarakat yang menolak tambang dan } \\
\text { biasanya beraliansi dengan WALHI ataupun LSM } \\
\text { lingkuangan lainnya. }\end{array}$ \\
\hline \multirow[t]{7}{*}{3} & Logistik & 15 & Nawakara & $\begin{array}{l}\text { Pihak kontraktor keamanan yang bertugas menjaga } \\
\text { keamanan kendaraan logistic yang keluar masuk PT } \\
\text { BSI }\end{array}$ \\
\hline & & 16 & Aset Protection & $\begin{array}{l}\text { Pihak karyawan PT BSI yang bertugas melakukan } \\
\text { perlindungan asset baik internal maupun external. }\end{array}$ \\
\hline & & 17 & Obvitnas & $\begin{array}{l}\text { Pihak aparat pemerintah yang bertugas menjaga } \\
\text { keamanan perusahaan yang merupakan objek vital } \\
\text { nasional }\end{array}$ \\
\hline & & 18 & Forpimka & $\begin{array}{l}\text { Pihak aparat pemerintah Kecamatan Pesanggaran yang } \\
\text { mempunyai wilayah kerja bertugas menjaga keamanan } \\
\text { kendaraan logistik keluar masuk PT BSI. }\end{array}$ \\
\hline & & 19 & $\begin{array}{l}\text { Kelompok Masyarakat } \\
\text { Sepanjang Jalur } \\
\text { Logistik }\end{array}$ & $\begin{array}{l}\text { Pihak masyarakat yang sering melakukan advokasi } \\
\text { terkait permasalahan jalan jalur kendaraan logsitik } \\
\text { (ada } 13 \text { kelompok) }\end{array}$ \\
\hline & & 20 & $\begin{array}{l}\text { SCM (Suply Chain } \\
\text { Management) PT BSI }\end{array}$ & $\begin{array}{l}\text { Pihak karyawan perusahaan yang bertugas melakukan } \\
\text { pembelian alat dan bahan untuk operasional } \\
\text { perusahaan berikut kelancaran transportasinya. }\end{array}$ \\
\hline & & 21 & PLN & Pihak BUMN yg berwenang menata kabel yang \\
\hline
\end{tabular}


22 Telkom

23 PU Bina Marga

24 Dinas Perhubungan

4 Operation $\quad 25$ Team blasting

26 Team OPP

27 Pokmas Wisata (Pantai Pulau Merah dan Pantai Mustika)

28 Masyarakat tapak Pihak masyarakat yang merupakan tetangga dekat tambang

5 CSR/Comdev 29 Masyarakat Sekitar

Tambang dalam wilayah IUP PT BSI

(dari beberapa komponen sesuai profesinya)

30 LSM pemberdayaan masyarakat

n.a Kelompok Masyarakat Wisata

31 Paguyuban tokoh lintas agama

32 Masyarakat di luar wilayah IUP

33 Paguyuban kepala desa Pesanggaran

34 Lembaga Mitra comdev Pihak penyedia jasa pelaksana kegiatan comdev

6 Security n.a Nawakara

n.a Team Aset Protection

n.a Masyarakat Sekitar Tambang

35 Perhutani

n.a Kelompok Masyarakat Sepanjang Jalur Logistik termasuk survey dan penelitian.

melintang di jalan jalur logistik dan poisisnya terlalu rendah sehingga sering ketabrak alat berat yang keluar masuk PT BSI

Pihak BUMN yang berwenang manta kabel melintang di jalan jalur logistik terlalu rendah sehingga sering ketabrak alat berat yang keluar masuk PT BSI

Pihak pemerintah yang bertanggung jawab memperbaiki jalan kelas jalan kabupaten-provinsi dan negara

Pihak pemerintah yang bertanggung jawab melakukan perbaikan lampu jalan dan memberikan ijin keluar masuknya kendaraan berat sesuai kelas kalan

Pihak karyawan PT BSI yang bertugas melakukan blasting dan mengendalikan agar suara tidak bising diatas ambang kendali dan menimbulkan debu.

Pihak karyawan PT BSI yang bertugas melakukan penghalusan batuan dan mengelola agar suara mesin tidak melebihi ambang yg telah ditetapkan.

Pihak Masyarakat yang terganggu adanya kegiatan operasional PT BSI dengan PT BSI

Pihak masyarakat baik individu yang berada di wilayah IUP PT BSI atau kelompok penerima program pemberdayaan di bidang kesehatan, Pendidikan, ekonomi, lapangan kerja, infrasturktur, kelembagaan, partisipasi lingungan hidup, serta social budaya dan agama.

Pihak LSM lokal yang bergerak di bidang pemberdayaan masyarakat

Pihak Kelompok Wisata Pulau Merah dan Pantai Mustika

Pihak masyarakat yang membantu mengkomunikasikan kegiatan community development atau kegiatan social keagamaan kepada jamaahnya.

Pihak masyarakat yang mengusulkan atau mendapatkan progam pengembangan masyarakat di luar wilayah IUP PT BSI

Pihak kepala desa yang bekerjasama dengan CSR PT BSI melalui bantuan dana melalui APBDes.

Pihak kontraktor keamanan yang bertugas menjaga keamanan asset PT BSI baik internal maupun BSI

Pihak karyawan PT BSI yang bertanggung jawab mengawasi kegiatan perlindungan asset PT BSI

Masyarakat sekitar tambang yang terkait dengan keamanan asset PT BSI berupa kayu atapun peralatan yang lain.

Pihak BUMN yang lahannya termasuk wilayah Ijin Usaha Pertambangan PT BSI

Pihak masyarakat yang sering melakukan advokasi terkait permasalahan jalan jalur kendaraan logsitik (ada 13 kelompok) yang berujung meminta bantuan 
36 Banser/Ansor

37 Kelompok Silat pemberdayaan ekonomi.

Pihak oranganisasi masyarakat yang melakukan pengamanan jalan ketika ada acara kemasyarakatan dan keagamaan.

Pihak kelompok masyarakat yang terlibat dalam melakukan pengamanan jalan ketika ada acara-acara kemasyarakatan.

\begin{tabular}{llll}
\hline 7 Contractor & n.a SCM & & $\begin{array}{l}\text { Pihak karyawan perusahaan yang bertugas melakukan } \\
\text { pembelian alat dan bahan untuk operasional } \\
\text { perusahaan melalui vendor. }\end{array}$ \\
38 Suplier local & $\begin{array}{l}\text { Pihak pengusaha lokal yang tertarik bekerjasama } \\
\text { menjadi supplier PT BSI dibidang barang atau jasa. } \\
\text { Pihak kontraktor dibidang catering yang membeli } \\
\text { bahan dari petani dan atau nelayan masyarakat sekitar } \\
\text { tambang. }\end{array}$ \\
\hline
\end{tabular}

Sumber: Analisis data team Community Relation PT BSI

Tabel 2. Daftar eksternal dan internal Stakeholders pada PT BSI

\begin{tabular}{|c|c|c|c|}
\hline No & Internal Stakeholders & No & Eksternal Stakeholders \\
\hline 1 & HRD PT BSI & 1 & HRD kontraktor \\
\hline 2 & HRD MMS & 2 & Pencari kerja \\
\hline 3 & Karyawan & 3 & Pemerintah Desa \\
\hline 4 & Serikat pekerja & 4 & Disnaker \\
\hline 5 & Dept. Environment PT BSI & 5 & Masyarakat Sekitar Tambang wilayah IUP \\
\hline 6 & Team Aset Protection & 6 & Dinas Lingkungan Hidup (Prov/Kab) \\
\hline 7 & Dept. Suplat Chain Management & 7 & LSM Lingkungan Hidup (WALHI, dsb) \\
\hline 8 & Team blasting & 8 & Nelayan \\
\hline \multirow[t]{22}{*}{9} & Team OPP & 9 & Kelompok Tolak Tambang \\
\hline & & 10 & Nawakara \\
\hline & & 11 & Obvitnas \\
\hline & & 12 & Forpimka \\
\hline & & 13 & $\begin{array}{l}\text { Kelompok Masyarakat Jalur logistic (13 } \\
\text { kelompok) }\end{array}$ \\
\hline & & 14 & $\begin{array}{l}\text { Pokmas Wisata (Patai Pulau Merah dan Pantai } \\
\text { Mustika) }\end{array}$ \\
\hline & & 15 & Masyarakat Tapak Tambang \\
\hline & & 16 & Kelompok masyarakat berdasar profesi \\
\hline & & 17 & LSM Pemberdayaan Masyarakat \\
\hline & & 18 & Paguyuban tokoh lintas agama \\
\hline & & 19 & Masyarakat diluar wilayah IUP \\
\hline & & 20 & Paguyuban Kepala Desa Kec. Pesangggaran \\
\hline & & 21 & Perhutani \\
\hline & & 22 & Banser/Ansor \\
\hline & & 23 & Kelompok Silat \\
\hline & & 24 & Suplier local (CV, Koperasi, PT) \\
\hline & & 25 & $\begin{array}{l}\text { Lembaga Mitra Comdev (Konsultan: Kesehatan, } \\
\text { dll) }\end{array}$ \\
\hline & & 26 & PT PBU \\
\hline & & 27 & PLN \\
\hline & & 28 & TELKOM \\
\hline & & 29 & Dinas PU Bina Marga \\
\hline & & 30 & Dinas Perhubungan \\
\hline
\end{tabular}

Sumber: Analisis data team Community Relation PT BSI

Dari Tabel 2. Dapat dilihat internal stakeholders yang dihandle oleh team Community relation sejumlah 9 pihak dan external stakeholders-nya sejumlah 30 pihak. 


\section{C.2. Analisis Enabler, Limiter dan Swinger Stakeholder PT BSI}

Enabler adalah pihak-pihak yang mendukung tercapainya tujuan perusahaan karena adanya kesamaan kepentingan. Limiter adalah pihak-pihak yang menghambat tercapainya tujuan perusahaan. Swinger adalah pihak yang kadang mendukung dan kadang menghambat tergantung dari kepentingan stakeholders secara subjektif. Berdasarkan pengamatan kelompok enabler, limiter dan swinger sebagaimana terlihat pada Tabel 3.

Tabel 3. Analisis Enabler, Limiter dan Swinger Stakeholder PT BSI

\begin{tabular}{|c|c|c|c|}
\hline No & Enabler & Limiter & Swinger \\
\hline 1. & HRD PT BSI & 1. Pencari kerja & 1. HRD kontraktor \\
\hline 2. & HRD MMS & $\begin{array}{l}\text { 2. LSM Lingk Hidup (WALHI, } \\
\text { dsb) }\end{array}$ & 2. Pemerintah Desa \\
\hline 3. & Karyawan & 3. Nelayan & 3. Disnaker \\
\hline 4. & Serikat pekerja & 4. Kelompok Tolak Tambang & $\begin{array}{l}\text { 4. Masy. Sekitar Tambang wilayah } \\
\text { IUP }\end{array}$ \\
\hline 5. & Dept. Environ PT BSI & 5. Pokmas jalur logistic $(13 \mathrm{kel})$ & 5. Forpimka \\
\hline 6. & Team Aset Protection & & $\begin{array}{l}\text { 6. Pokmas Wisata (P. } \\
\text { Merah/Mustika) }\end{array}$ \\
\hline 7. & Dept. SCM & & 7. Masyarakat Tapak Tambang \\
\hline 8. & Team blasting & & 8. Pokmas berdasar profesi \\
\hline 9. & Team OPP & & 9. LSM Pemberdayaan Masyarakat \\
\hline 10. & DLH (Prov/Kab) & & 10. Masyarakat di luar wilayah IUP \\
\hline 11. & Nawakara & & 11. Paguyuban Kades. Pesanggaran \\
\hline 12. & Obvitnas & & 12. Perhutani \\
\hline 13. & $\begin{array}{l}\text { Paguyuban tokoh lintas } \\
\text { agama }\end{array}$ & & 13. Kelompok Silat \\
\hline 14. & Banser/Ansor & & 14. TELKOM \\
\hline 15. & Suplier local (CV, Kop, PT) & & 15. PLN \\
\hline 16. & PT PBU (catering) & & 16. PU Bina Marga \\
\hline 17. & Lembaga mitra comdev & & 17. Dinas Perhubungan \\
\hline
\end{tabular}

Sumber: Analisis data team Community Relation PT BSI

Dari Tabel 3. Dapat dilihat bahwa enabler 17 kelompok, limiter ada 5 kelompok yang perlu mendapatkan perhatian dan pengelolaan yang serius. Demikian juga ada 17 kelompok swinger yang apabila tidak dikelola dengan baik akan berubah menjadi kelompok limiter.

\section{C.3. Analisis Power Interest Grid pada PT BSI}

Analisis ini bertujuan untuk mengetahui kekuatan masing-masing stakeholders dan usaha seperti apa yang sebaiknya dilakukan untuk menghandle masing-masing stakehodlers dengan karakter, kekuatan dan kepentingan yang berbeda. Hasil analisis power grid sebagaimana terlihat pada Tabel 4.

Ringkasan dari Analisis Power grid seperti terlihat pada Tabel 5. Dari ringkasan analisis tersebut Community relation PT BSI masih harus mencurahkan perhatian dan tenaganya untuk menjaga komunikasi yang baik (keep informed) $46 \%$ dan menjaga hubungan baik (Keep satisfied) $20 \%$ dan harus mengahadapi key player sejumlah $28 \%$.

\section{C.4. Analisis ketergantungan stakeholders dengan PT BSI}

Analisis ini digunakan untuk mengukur dan menilai sejauh mana ketergantungan suatu stakeholders pada perusahaan yang dikenal dengan Resources Dependency Theory (Freeman, 2007). Berdasarkan Resource Dependency Theory kebutuhan perusahaan akan suatu sumber daya membua peluang pihak lain mengendalikan perusahaan . 
Tabel 4. Analisis Power Grid Pada PT BSI

\begin{tabular}{|c|c|c|c|}
\hline & & \multicolumn{2}{|c|}{ Minat (Interest) } \\
\hline & & Rendah & Tinggi \\
\hline 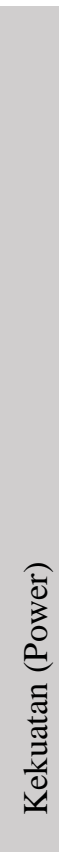 & $\begin{array}{l}\text { जٓ } \\
\text { एँ } \\
\simeq\end{array}$ & $\begin{array}{l}\text { Minimal effort } \\
\text { 1. Masyarakat di luar diluar IUP } \\
\text { 2. LSM Pemberdayaan Masyarakat }\end{array}$ & $\begin{array}{l}\text { Keep informed } \\
\text { 1. Mitra Comdev (layanan kesehatan, } \\
\text { konsultan) } \\
\text { 2. Suplier local } \\
\text { 3. LSM Lingkungan } \\
\text { 4. Kelompok Tolak Tambang } \\
\text { 5. Pokmas Wisata } \\
\text { 6. Masyarakat Sekitar Tambang wilayah } \\
\text { IUP } \\
\text { 7. Forpimka } \\
\text { 8. Perhutani } \\
\text { 9. Disnaker } \\
\text { 10. Dept. Security/Aset Protection } \\
\text { 11. Team Blasting } \\
\text { 12. Dept. SCM } \\
\text { 13. Nawakara } \\
\text { 14. SKPD terkait progam comdev } \\
\text { 15. Obvitnas } \\
\text { 16. Team OPP } \\
\text { 17. Dept. Environment PT BSI } \\
\text { 18. Paguyuban tokoh lintas agama }\end{array}$ \\
\hline & 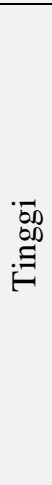 & $\begin{array}{l}\text { Keep Satisfied } \\
\text { 1. Dinas Lingkungan Hidup } \\
\text { 2. Kelompok Silat } \\
\text { 3. Disnaker } \\
\text { 4. Banser/Ansor NU } \\
\text { 5. Dinas PU } \\
\text { 6. Dinas Perhubungan } \\
\text { 7. Telkom } \\
\text { 8. PLN }\end{array}$ & $\begin{array}{l}\text { Key Player } \\
\text { 1. Masyarakat jalur logistic } \\
\text { 2. Pemerintah desa } \\
\text { 3. Paguyuban Kepala Desa } \\
\text { 4. Nelayan } \\
\text { 5. Pencari kerja } \\
\text { 6. Masyarakat Tapak Tambang } \\
\text { 7. HRD PT BSI } \\
\text { 8. HRD Kontraktor } \\
\text { 9. HRD MMS } \\
\text { 10. Serikat pekerja } \\
\text { 11.PT PBU }\end{array}$ \\
\hline
\end{tabular}

Sumber: Analisis data team Community Relation PT BSI

Tabel 5. Ringkasan Analisis Power Grid Pada PT BSI

\begin{tabular}{llrc}
\hline No & Pengelolaan & Jumlah & Prosentase \\
\hline 1 & Minimal effort & 2 & $0.05 \%$ \\
2 & Keep informed & 18 & $46.15 \%$ \\
3 & Keep satisfied & 8 & $20.51 \%$ \\
4 & Key Player & 11 & $28.20 \%$ \\
\hline \multicolumn{2}{l}{ Sumber: Analisis data team Community Relation PT BSI }
\end{tabular}

Dari tabel tersebut PT BSI memusatkan perhatian pada kelompok dengan stakeholder power dan high interdependence. Pihak pihak yang berada dalam kategori tersebut memiliki power yang kuat selain itu PT BSI mempunyai ketergantungan kepada pihak-pihak di dua kategori tersebut. Memberikan perhatian lebih pada kedua kategori tersebut akan membuat PT BSI lebih optimal dalam mengatasi konflik-konflik yang ada. 
Tabel 6. Tipologi Ketergantungan antara Stakeholders dan Perusahaan PT BSI

\begin{tabular}{|c|c|}
\hline \multicolumn{2}{|c|}{ Apakah stakeholders bergantung pada perusahaan } \\
\hline Tidak & Ya \\
\hline $\begin{array}{l}\text { Low interdependence } \\
\text { 1. Masyarakat di luar diluar IUP } \\
\text { 2. Pencari kerja } \\
\text { 3. Pemerintah desa } \\
\text { 4. Disnaker } \\
\text { 5. SKPD terkait progam comdev } \\
\text { 6. Masyarakat (sekitar tambang, jalur } \\
\text { logistic) } \\
\text { 7. LSM Lingkungan } \\
\text { 8. Nelayan } \\
\text { 9. Kelompok Tolak Tambang } \\
\text { 10. Pokmas Wisata } \\
\text { 11. Masyarakat Tapak Tambang } \\
\text { 12. Masyarakat Sekitar Tambang } \\
\text { (kelompok profesi sasaran program } \\
\text { comdev) } \\
\text { 13. LSM Pemberdayaan Masyarakat } \\
\text { 14. Banser/Ansor NU } \\
\text { 15. Kelompok Silat }\end{array}$ & $\begin{array}{l}\text { Firm Power } \\
\text { 1. Mitra Comdev (layanan kesehatan, } \\
\text { konsultan) } \\
\text { 2. Suplier local }\end{array}$ \\
\hline $\begin{array}{l}\text { Stakeholders Power } \\
\text { 1. Perhutani } \\
\text { 2. Forpimka } \\
\text { 3. Paguyuban Kepala Desa } \\
\text { 4. Disnaker } \\
\text { 5. Dinas Lingkungan Hidup } \\
\text { 6. Dinas PU } \\
\text { 7. Dinas Perhubungan } \\
\text { 8. TELKOM } \\
\text { 9. PLN }\end{array}$ & $\begin{array}{l}\text { High interdependence } \\
\text { 1. Manajemen (External, } \\
\text { Internal/Operation) } \\
\text { 2. Dept. Environment PT BSI } \\
\text { 3. Dept. Security/Aset Protection } \\
\text { 4. Team Blasting } \\
\text { 5. Team OPP } \\
\text { 6. Dept. SCM } \\
\text { 7. HRD PT BSI } \\
\text { 8. HRD Kontraktor } \\
\text { 9. HRD MMS } \\
\text { 10. Nawakara } \\
\text { 11. Obvitnas } \\
\text { 12. Serikat pekerja } \\
\text { 13. PT PBU }\end{array}$ \\
\hline
\end{tabular}

Sumber: Analisis data team Community Relation PT BSI

Tabel 7. Ringkasan Ketergantungan antara Stakeholder dan Perusahaan pada PT BSI

\begin{tabular}{llcc}
\hline No & Hubungan Ketergantungan & Jumlah & Prosentase \\
\hline 1 & Low Interdependence & 15 & $42.80 \%$ \\
2 & Firm Power & 2 & $5.70 \%$ \\
3 & Stakeholders Power & 9 & $23.07 \%$ \\
4 & High Interdependence & 13 & $37.20 \%$ \\
\hline & Total & 39 & $100.0 \%$ \\
\hline
\end{tabular}

Sumber: Analisis data team Community Relation PT BSI

\section{C.3. Analisis Strategic Management}

Untuk memetakan posisi masing-masing stakeholders untuk membuat prioritas startegi terbaik pada PT BSI maka digunakan metoda strategic management (Freeman, 2007). Teori mengelompokkan stakeholders berdasarkan kemampun stakeholders untuk mengancam dan keinginan stakeholders bekerja sama dengan PT BSI. 
Tabel 8. Analisis Posisi Strategic Stakeholders pada PT BSI

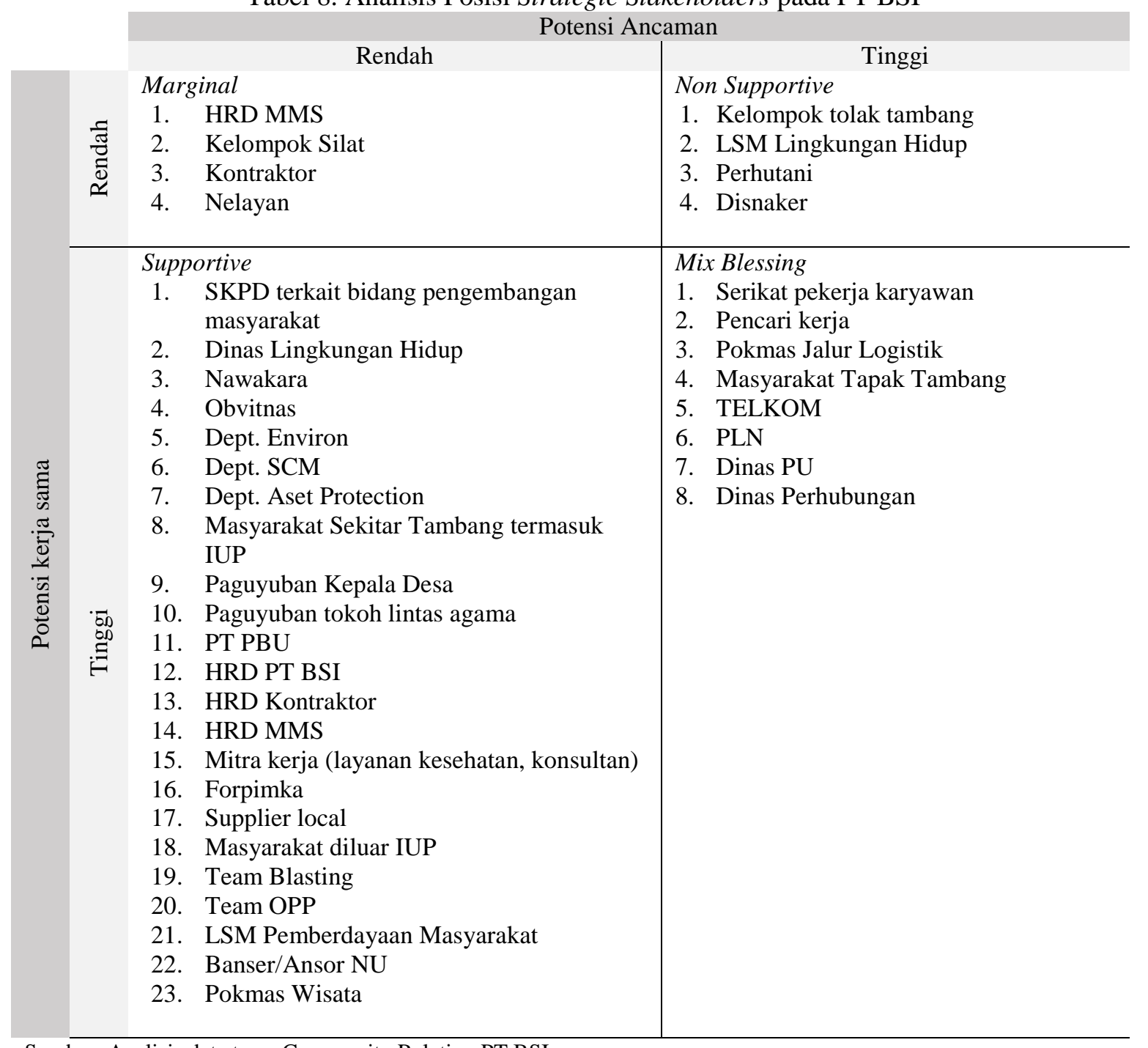

Sumber: Analisis data team Community Relation PT BSI

Stakeholders pada posisi_marginal ada 4 stakeholders merupakan stakeholders dengan potensi kerjasama dan potensi ancaman yang rendah. PT BSI mengambil sikap untuk mempertahankan posisi saat ini dan meneruskan program strategis yang sudah dijalankan.

Stakeholders dengan potensi non supportive terdiri dari 4 stakeholders merupakan stakeholders dengan potensi kerjasama rendah dan potensi ancaman tinggi, PT BSI mengambil sikap untuk defensive yakni bertahan dari kemungkinan-kemungkian ancaman yang akan menimpa. Stakeholders dengan potensi supportive terdiri dari 23 stakeholders merupakan stakeholders dengan potensi kerjasama tinggi dan potensi ancaman rendah, PT BSI mengambil sikap untuk offensive yakni terus melakukan kegiatan kerjsama yang innovative yang bisa mendorong untuk lebih bermanfaat. Stakeholders dengan potensi mix blessing terdiri dari 8 stakeholders merupakan stakeholders dengan potensi kerjasama tinggi dan potensi ancaman tinggi, dapat memberikan dampak yang baik dan yang buruk jika PT BSI tidak dapat mengelola dengan baik. PT BSI mengambil sikap untuk swing yakni terus melakukan kegiatan kerjsama sambal terus mengontrol kemungkinan-kemungkinan berdampak buruk dikelak kemudian hari. 
Tabel 9. Ringkasan Posisi Strategic Stakeholders pada PT BSI

\begin{tabular}{llrr}
\hline No & Posisi Startegic & Jumlah & Prosentase \\
\hline 1 & Marginal & 4 & $10.25 \%$ \\
2 & Non Supportive & 4 & $10.25 \%$ \\
3 & Supportive & 23 & $58.97 \%$ \\
4 & Mix Blessing & 8 & $20.51 \%$ \\
\hline & Total & 39 & $100.00 \%$ \\
\hline
\end{tabular}

Sumber: Analisis data team Community Relation PT BSI

\section{C.4. Realisasi Aksi Masa}

Intensitas aksi massa pada PT BSI dari tahun 2015 - 2019 sebagaimana terlihat pada Gambar 1.

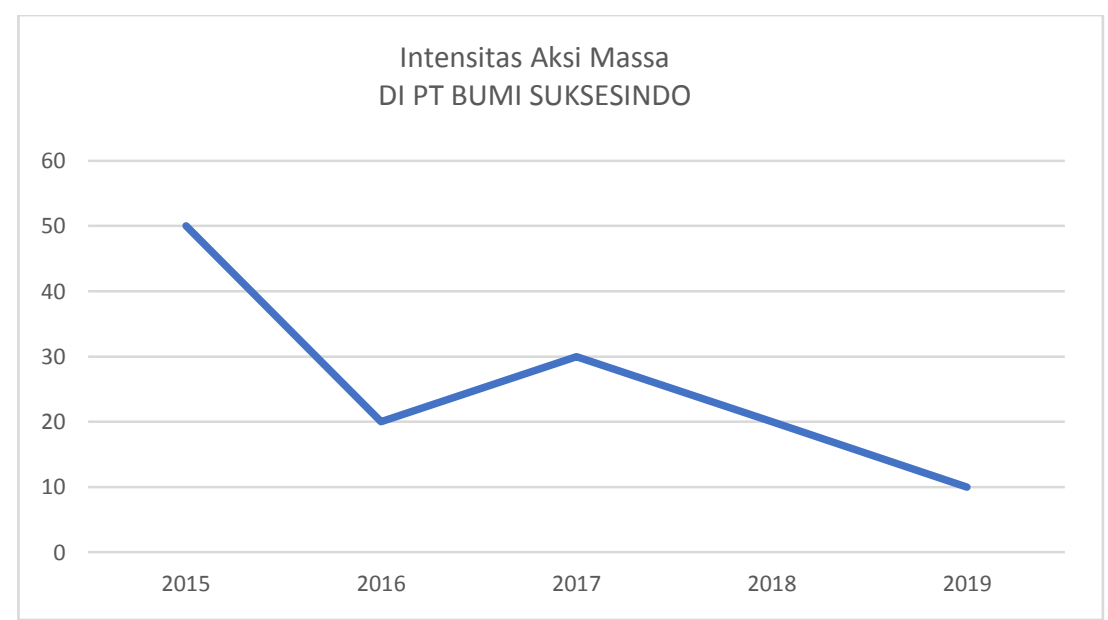

Sumber: Analisis data team Community Relation PT BSI

Gambar 1. Realisasi Intensitas Aksi Massa PT BSI 2015-2019

Intensitas aksi masa tertinggi ada tahun 2015 dimana terjadi pembakaran beberapa fasilitas PT BSI. Pada tahun 2016 sampai 2019 terjadi naik turun aksi masa tanpa kehilangan waktu operasional dan terendah pada tahun 2019 sampai tulisan ini selesai sebayak sekali pertahun dengan demonstrasi di depan pintu masuk PT BSI.

\section{KESIMPULAN}

Efektivitas secara umum menunjukan sampai seberapa jauh tercapainya suatu tujuan yang terlebih dahulu ditentukan. Hal tersebut sesuai dengan pengertian efetivitas menurut Moore D.Kenneth Dalam Moh Syarif (2015:1) efektivitas suatu ukuran yang menyatakan seberapa jauh target (kuantitas, kualitas dan waktu) telah tercapai, atau makin besar presentase target yang dicapai, makin tinggi efektivitasnya. Target yang ingin dicapai dalam kinerja Community Relation PT BSI adalah tidak ada aksi masa (Zero Mass Action) yang mengakibatkan berhentinya operasi perusahaan.

Kesimpulan yang dapat ditarik dari pengalaman penerapan stakeholders mapping ini adalah:

1. Stakeholders mapping yang diterapkan mulai pada tahun 2019 terbukti efektif mencegah terjadi intensitas aksi masa dibandingkan dengan intensitas aksi masa yang terjadi dari tahun sebelumnya. 
2. Keberhasilan ini adalah hasil kerjasama antara team external relation bersama team internal PT BSI dan tentu saja karena kontribusi dari pemerintah desa.

\section{UCAPAN TERIMAKASIH}

Team Community Relation mengucapkan terimakasih kepada para pihak yang telah membantu tercapainya kinerja tahun 2019:

1. Kepada Yth. Bapak Boyke Abidin Direktur External Relation, Bapak Katamsi Ginano General Manager External Relation, Bapak Sudarmono Senior Manager External Relation yang telah memberikan arahan dan bimbingan serta kesempatan kepada kami untuk terus berkarya memberikan yang terbaik bagi PT BSI.

2. Kepada Yth. Paguyuban Kepala Desa Pesanggaran, Forpimka Pesanggaran, serta Forpimda Banyuwangi yang telah bekerjasama bahu membahu dilapangan sehingga bisa permasalahan sesulit apapun dapat dihadapi dengan perasaaan ringan dan mudah.

3. Tidak lupa kepada teman-teman seperjuangan dari Community Development yang dengan peran sertanya masyarakat jadi lebih baik lagi berhubungan dengan PT B

\section{DAFTAR PUSTAKA}

Freeman, R.E., Harrison, J.S. \& Parmar, B (2007). Stakeholder capitalism. Journal of Business Ethics. 74, 4 